CASE REPORT

\title{
Nodular regenerative hyperplasia of the liver and coeliac disease: potential role of $\lg A$ anticardiolipin antibody
}

\author{
A Austin, E Campbell, P Lane, E Elias
}

Gut 2004;53:1032-1034. doi: 10.1136/gut.2003.036806

Nodular regenerative hyperplasia (NRH) of the liver is a rare disorder that is often associated with connective tissue disorders, haematological malignancy, or drugs, and is a cause of non-cirrhotic portal hypertension. We describe two cases of NRH in individuals with adult coeliac disease and $\lg \mathrm{A}$ anticardiolipin antibodies. We discuss the potential impact of this observation on the understanding of the pathogenesis of $\mathrm{NRH}$.

$\mathrm{N}$ odular regenerative hyperplasia (NRH) of the liver is an uncommon pathological finding associated, in most cases, with rheumatic and haematological diseases and with drugs, including immunosuppressive agents such as azathioprine. ${ }^{2}$ In autopsy studies, NRH is often associated with non-cirrhotic portal hypertension. ${ }^{1}$ $\mathrm{NRH}$ is characterised by the presence of nodules of regenerative hepatocytes, without fibrous septa, distributed diffusely across the hepatic parenchyma. ${ }^{3}$ Although its pathogenesis remains unclear, $\mathrm{NRH}$ is thought to result from liver regeneration after ischaemia induced injury. An intrahepatic microvascular occlusive mechanism has been proposed $^{4}$ and a prothombotic disorder has been reported in half of cases presenting with non-cirrhotic portal hypertension. ${ }^{5}$

Antiphospholipid antibodies (aPL) are a heterogeneous group of circulating autoantibodies found in the sera of healthy subjects and patients with autoimmune and infectious diseases. They have been implicated in the occurrence of thrombocytopenia and thrombotic events. An association between IgG aPL and NRH was first reported in patients with systemic lupus erythematosis. ${ }^{6}$

We describe two cases of NRH complicated by portal hypertension and associated with IgA anticardiolipin antibodies (aCL) in patients with adult coeliac disease. We discuss the possible relationships between coeliac disease, IgA anticardiolipin antibodies, and NRH.

\section{CASE REPORTS}

\section{Case 1}

A 55 year old female presented with ascites, weight loss, and thrombocytopenia $\left(76 \times 10^{9} / \mathrm{l}\right)$, having been diagnosed with coeliac disease 24 years earlier. Compliance with a gluten free diet had been suboptimal. Her liver function tests were abnormal on all occasions (aspartate aminotransferase (AST) $1-3 \times$ normal, alkaline phosphatase (ALP) $1-2 \times$ normal, bilirubin $85-117 \mu \mathrm{mol} / \mathrm{l}$, albumin $<32 \mathrm{~g} / \mathrm{l}$, international normalised ratio (INR) $\leqslant 1.3$ ). The spleen was not enlarged and the portal vein was patent. A computed tomography scan of the chest and abdomen did not identify lymphadenopathy and the hepatic veins were patent. The hepatic venous pressure gradient measured $10 \mathrm{~mm} \mathrm{Hg}$. A liver biopsy demonstrated foci of NRH with loss of portal vein branches.
In addition, features of a chronic biliary process were present but not suggestive of primary biliary cirrhosis. There was no evidence of cirrhosis. A biopsy taken five years earlier at the referring hospital showed an identical process. Following liver biopsy, she developed intractable haemorrhage with features of disseminated intravascular coagulation and died.

\section{Case 2}

A 35 year old male presented with ascites, weight loss, and thrombocytopenia $\left(42 \times 10^{9} / 1\right)$. A liver biopsy demonstrated $\mathrm{NRH}$ and he was diagnosed with coeliac disease on duodenal biopsy the following year. He took a gluten free diet intermittently and suffered episodic ascites and confusion. Age 43 years, he was referred for liver transplantation but prior to assessment suffered a stroke (right parietal lobe infarct). His liver function tests were abnormal (AST 114 (normal range 5-43), ALP 668 (normal range 17-330), bilirubin $39 \mu \mathrm{mol} / \mathrm{l}$ (normal range 1-22), albumin $32 \mathrm{~g} / \mathrm{l}$ (normal range 34-51), INR 1.3). He remained positive for IgA endomysial antibodies and duodenal biopsy demonstrated persistent subtotal villous atrophy. The liver was small but he improved slowly on a strict gluten free diet. Acute portal vein thrombosis precipitated a further deterioration and he died.

In both cases, total IgA levels were elevated but autoantibodies, including antimitochondrial and antineutrophil cytoplasmic antibodies, were negative. A full thrombophilia screen, including assays for protein $\mathrm{C}$ and $\mathrm{S}$ (function and protein), antithrombin III, and activated protein $C$ resistance was negative in both cases. Results of aCL antibody and anti$\beta 1$ glycoprotein 1 antibody assays are shown in table 1 .

\section{DISCUSSION}

We have reported two cases of NRH associated with IgA aCL and longstanding coeliac disease (poor dietary compliance). Our current understanding of NRH is that obliteration of small portal branches causes atrophy of downstream lobules and initiates compensatory hyperplasia in adjacent lobules with an intact portal venular supply. A number of thrombophilic disorders, including polycythemia vera, primary thrombocythemia, ${ }^{4}$ protein $S$ deficiency, ${ }^{5}$ and IgG antiphospholipid syndrome (APS) ${ }^{6}$ are associated with NRH. APS is a systemic autoimmune disorder characterised by a combination of arterial and/or venous thrombosis or recurrent pregnancy loss, and thrombocytopenia with the presence of elevated titres of aPL antibodies. aPL are autoantibodies directed against anionic phospholipids or protein/phospholipid complexes (commonly containing $\beta 2$ glycoprotein I ( $\beta 2$ GPI) or prothrombin, but also protein $C$, protein $S$, and annexin V) measured in solid phase immunoassays as aCL

Abbreviations: $\mathrm{NRH}$, nodular regenerative hyperplasia; $\mathrm{aCL}$, anticardiolipin antibodies; aPL, antiphospholipid antibodies; APS, antiphospholipid syndrome; AST, aspartate aminotransferase; ALP, alkaline phosphatase; INR, international normalised ratio; $\beta 2-\mathrm{GPI}, \beta 2$ glycoprotein I 
Table 1 Results of anticardiolipin antibody and anti- $\beta 2$ glycoprotein 1 antibody assays in the two patients

\begin{tabular}{lllll}
\hline & \multicolumn{2}{l}{ Anticardiolipin antibody $(\mathrm{U} / \mathrm{ml})$} & \\
\cline { 2 - 5 } & IgG & IgM & IgA & \\
& [NR 0-12] & [NR 0-10] & [NR 0-13] & Anti- $\boldsymbol{\beta 2}$ glycoprotein 1 \\
\hline Case 1 & $<12$ & $<10$ & 44 & Negative \\
Case 2 & $<12$ & $<10$ & 18 & Borderline positive \\
\hline
\end{tabular}

$\mathrm{NR}$, normal range.

antibodies or detected in phospholipid dependent clotting tests as lupus anticoagulant. ${ }^{7}$

In the cases described here, aCL antibodies were associated with abnormal thrombosis, bleeding, and prolonged persistent thrombocytopenia in the absence of other features of hypersplenism. The exact mechanism by which aCL antibodies are produced is unclear. Anionic phospholipids (for example, phosphatidylserine) are regular constituents of the inner leaflet of the cell membrane that are only exposed on the outside of the cell membrane during apoptosis, or by damaged endothelial cells and activated platelets during blood coagulation. In the latter situation, membranes containing phosphatidylserine provide the catalytic surface that serves as a point of assembly for the prothrombinase complex. In an animal model, systemic exposure to apoptotic cells induced the formation of aCL. ${ }^{8}$ We postulate that apoptosis is the link between coeliac disease and an aPL associated vasculopathy which leads to NRH. Coeliac disease is caused by an abnormal $\mathrm{T}$ cell mediated inflammatory response to dietary gluten and the hallmark autoantibody is produced against the tissue and cell associated protein transglutaminase. The mechanism thought to evoke this anti-self antibody begins with tranglutaminase cross linking and forming a complex with gliadin which is rich in glutamine. Transglutaminase specific B cells take up gluten/ transglutaminase complexes and present $\mathrm{T}$ cell epitopes to gluten specific $\mathrm{T}$ cells, resulting in $\mathrm{T}$ cell help for the production of antibodies against the self-protein transglutaminase. ${ }^{9}$ Transglutaminase is also expressed in apoptotic cells where it cross links glutamine residues in membrane proteins, thereby protecting apoptotic cells from disintegrating and releasing their contents. We hypothesise that when this process occurs in apoptotic enterocytes during active coeliac disease, ${ }^{10}$ complexes of gliadin and apoptotic cells might lead to $\mathrm{T}$ cell help for not only antibody responses to transglutaminase but also the anionic phospholipids in the apoptotic cell membranes leading to generation of aCL. This phenomenon of epitope spreading is seen in other autoimmune diseases where autoantibodies initially directed to an individual self-component spread to other closely associated cellular components. ${ }^{11}$ In support of this hypothesis, aCL antibodies have been found in $14 \%$ of coeliac patients, with significantly higher levels of aCL in untreated disease compared with coeliacs on a gluten free diet. ${ }^{12}$

The reported prevalence of IgA aCL in studies of patients with SLE or APS varies from $1 \%$ to $44 \%$; in one group of SLE patients, IgA aCL was the most frequent aCL isotype present. ${ }^{13}$ IgA aCL have not been included in the diagnostic criteria of the APS because of doubts over their pathological significance. However, in a mouse model, aCL IgA induced thrombosis and required $\beta 2$-GPI to bind to cardiolipin antigen. ${ }^{14}$ Furthermore, associations between elevated IgA aCL and thrombotic events, small vessel vasculitis, cutaneous leucocytoclastic vasculitis, thrombocytopenia, recurrent fetal loss, and spontaneous abortions have been described..$^{15}$ In coeliac disease, IgA aCL are the most likely class of antibody to be evoked because immunisation occurs in gut associated lymphoid tissue. The concentration of IgA aCL would be expected to be higher in portal venous blood compared with the systemic circulation, and portal vein radicles would be the most likely site to be affected by thrombotic complications.

In conclusion, we have described two cases of NRH associated with IgA aCL and evidence of poorly compliant coeliac disease. We suggest $\mathrm{T}$ cell help from gluten specific $\mathrm{T}$ cells is responsible for driving the IgA autoantibody response to both transglutaminase and protein/phospholipid complexes, leading to the formation of IgA aCL. IgA aCL then trigger thrombosis in small portal vein radicles, which drain the inflamed small intestine, leading to liver injury with consequent hyperplasia of the surrounding tissue. This observation adds to the list of prothrombotic conditions such as primary myeloproliferative disorders, anticoagulant protein deficiencies, and APS associated with non-cirrhotic portal hypertension. ${ }^{5}$

\section{Authors' affiliations}

A Austin, E Campbell, E Elias, The Liver Unit, University Hospital Birmingham NHS Trust, Edgbaston, Birmingham, UK

P Lane, MRC Centre for Immune Regulation, IBR Wellcome Building,

Medical School, University of Birmingham, Birmingham, UK

Correspondence to: Professor E Elias, The Liver Unit, University Hospital Birmingham NHS Trust, Edgbaston, Birmingham B15 2TU, UK; elwyn.elias@uhb.nhs.uk

Revised version received 5 February 2004

Accepted for publication 6 February 2004

\section{REFERENCES}

1 Wanless IR. Micronodular transformation (nodular regenerative hyperplasia) of the liver: a report of 64 cases among 2,500 autopsies and a new classification of benign hepatocellular nodules. Hepatology 1990;1 1:787-97

2 Perez Ruiz F, Orte Martinez FJ, Zea Mendoza AC, et al. Nodular regenerative hyperplasia of the liver in rheumatic diseases: report of seven cases and review of the literature. Semin Arthritis Rheum 1991;21:47-54.

3 Stromeyer FW, Ishak KG. Nodular transformation (nodular "regenerative" hyperplasia) of the liver. A clinicopathologic study of 30 cases. Hum Pathol $1981 ; 12: 60-71$.

4 Wanless IR, Godwin TA, Allen F, et al. Nodular regenerative hyperplasia of the liver in hematologic disorders: a possible response to obliterative portal venopathy. A morphometric study of nine cases with an hypothesis on the pathogenesis. Medicine (Baltimore) 1980;59:367-79.

5 Hillaire S, Bonte $\mathrm{E}$, Denninger $\mathrm{MH}$, et al. Idiopathic non-cirrhotic intrahepatic portal hypertension in the West: a re-evaluation in 28 patients. Gut 2002;51:275-80.

6 Perez Ruiz F, Zea Mendoza AC, Orte Martinez FJ. Antiphospholipid antibodies may play a role in pathogenesis of nodular regenerative hyperplasia of the liver. Br J Rheumatol 1990;29(suppl 2):107.

7 Wilson WA, Gharavi AE, Koike T, et al. International consensus statement on preliminary classification criteria for definite antiphospholipid syndrome: report of an international workshop. Arthritis Rheum 1999;42:1309-11.

8 Mevorach D, Zhou JL, Song X, et al. Systemic exposure to irradiated apoptotic cells induces autoantibody production. J Exp Med 1998;188:387-92.

9 Sollid LM. Coeliac disease: dissecting a complex inflammatory disorder. Nat Rev Immunol 2002;2:647-55.

10 Moss SF, Attia L, Scholes JV, et al. Increased small intestinal apoptosis in coeliac disease. Gut 1996;39:811-17. 
11 McCluskey J, Farris AD, Keech CL, et al. Determinant spreading: lessons from animal models and human disease. Immunol Rev 1998;164:209-29.

12 Lerner A, Blank M, Lahat $N$, et al. Increased prevalence of autoantibodies in celiac disease. Dig Dis Sci 1998:43:723-6.

13 Weidmann CE, Wallace DJ, Peter JB, et al. Studies of $\lg G$, IgM and IgA antiphospholipid antibody isotypes in systemic lupus erythematosus. J Rheumatol 1988;15:74-9.
14 Pierangeli SS, Liu XW, Barker JH, et al. Induction of thrombosis in a mouse model by $\lg G$, IgM and IgA immunoglobulins from patients with the antiphospholipid syndrome. Thromb Haemost 1995;74:1361-7.

15 Lopez LR, Santos ME, Espinoza LR, et al. Clinical significance of immunoglobulin $A$ versus immunoglobulins $G$ and $M$ anti-cardiolipin antibodies in patients with systemic lupus erythematosus. Correlation with thrombosis, thrombocytopenia, and recurrent abortion. Am J Clin Pathol 1992;98:449-54. 